\title{
Single Incision Laparoscopic Surgery-An Overview and Current Status
}

\author{
Amit Goel \\ Army College of Medical Sciences, New Delhi, India \\ Email: gamit11@rediffmail.com
}

Received August 15, 2012; revised September 30, 2012; accepted October 9, 2012

\begin{abstract}
Single incision laproscopic surgery is an alternative to conventional multiport laproscopy. Natural orifice transluminal endoscopic surgery term coined by a Consortium in 2005 remains a research technique with few clinical cases. Single incision surgery offers advantage of better cosmesis, reduced incisions, lesser hernias, decreased pain and infections. Long learning curves and cost of instrumentation are the difficulties encountered in its propagation. Single incision laproscopic surgery is an evolving technique for advanced laproscopic centers. This article outlines the overview of devices and instruments and the techniques, feasibility of single incision laproscopic surgery.
\end{abstract}

Keywords: Notes; Sils; Ports; Endoscopy; Laparoscopy

\section{Introduction}

Conventional multiport minimal access surgery has been established as gold standard for many abdominal surgical procedures. In its endeavor to reduce scarring and trauma, surgeon and instrument industry combined their ingenuity to promote two new approaches for laparoscopic surgery, Natural orifice transluminal endoscopic surgery (NOTES) and Single incision laparoscopic surgery. NOTES leaves no scar but requires entry into peritoneal cavity with use of flexible endoscopes by perforation of a hollow viscus the stomach, oesophagus, colon and bladder whereas SILS requires a single port of entry with multiple articulating instruments introduced through that port with optics to perform various abdominal procedures which were earlier performed by multiple ports in conventional laproscopic surgery.

\section{Material and Methods}

It requires various types of endoscopes, instrumentation and techniques. Single incision laparoscopic surgery performs these procedures as multiport through one incision at umbilicus. A vast variety of hand instruments have evolved which are curved, coaxial and articulating having greater degree of freedom. NOTES interventions can be classified as "hollow visceral transperitoneal" which may be transgastric, transoesophageal, transcolonic, transvesical access to peritoneal cavity by planned perforation of a hollow viscus. The second approach "squamous conduit intraperitoneal" is transvaginal or a transanal-direct access to the peritoneal cavity. Hollow visceral transperitoneal requires interventional flexible technologies. Squamous conduit intraperitoneal is performed with existing laparoscopic instrumentation with rigid optics. Concept of SILS is attributed to Dr. Raimund Wittmoser, the father of modern thoracoscopic surgery.

Many instrument companies have produced single incision laparoscopic surgery port. Vast majority of these are disposable with exception of two reusable SILS ports namely X-PORT (STORZ TUTTILINGEN GERMANY) and ENDOCONE designed and developed at Institute of medical science and technology in Dundee in association with Storz. ENDOCONE has a detachable bulk which contains six lateral valved inlets that allow the insertion of large instruments including staplers. The surgeon is able to use three instruments and an optic at any one time during the course of operation. The instrumentation for SILS has improved with development of proximally deviated curved coaxial articulating instruments. Intracorporeal suturing is greatly facilitated with introduction of $5 \mathrm{~mm}$ hand held surgical manipulators with six degree of freedom. SILS procedure has been used for wide range of laparoscopic operations like colorectal resections, bariatric operations, nephrectomies, cholecystectomy and splenectomy.

\section{Discussion}

The first description of procedure to be known as natural orifice transluminal endoscopic surgery is credited to Kallo et al. in 2000 where they demonstrated the feasibility of peroral transgastric endoscopic approach to peritoneal cavity [1]. Gettman and colleagues in 2002 reported 
series of transvaginal porcine nephrectomies [2]. Rao and Reddy reported the first human cases of NOTES in 2004 with transgastric appendicectomy [3]. In July 2005, there was meeting of American Society of Gastrointestinal Endoscopy (ASGE) and Society of American Gastrointestinal and Endoscopic Surgeons. The deliberations of this group called Natural Orifice Surgery Consortium for Assessment and Research (NOSCAR group) was published as a white paper of ASGE/SAGES group on NOTES [4]. Pure NOTES is that which is only performed through natural orifices like transgastric, transesophageal, transcolonic and transvescical routes. NOSCAR group emphasized the need for institutional review for doing any human cases. Rendevous NOTES has been used to describe an approach where more than one portal of entry is used [5]. Robotic NOTES is new development using Da Vinci surgical robot (INTUITIVE SURGICAL, SUNNYVALE, CA) in animals to perform reconstructive surgery [6].

Gastrointestinal endoscopists are most familiar with transgastric route. The primary difficulty is tedious orientation after retroflexing the scope for cholecystectomy and upper abdominal procedures [7]. Vaginal routes have had most success as closure of vagina is easy and possible with rigid laproscopic instruments. The act of causing perforation to viscus may be detrimental if closure of the hollow viscus is insecure.

Single incision laproscopic surgery for cholecystectomy was described by Navarre et al. in 1997 and later Piskin et al. in 1999 [8]. The first cases of single port access device in form of prototype of R-Port was done by Rao et al. and reported to world congress endourology in 2007 [9]. The R-Port was single gel interphase that could be perforated to get the instruments inside the abdomen. This led to development of triports and quad ports available today. The articulating instruments could be introduced through these ports for better angulation and triangulation. A multidisciplinary consortium of surgeons met at Cleveland clinic in July 2008 suggested standardization for reporting these surgeries [10]. Since the introduction of single port access in 2007 hundreds of cases have been performed. The only randomized study conducted between SILS and laparoscopic surgery showed improvement in pain scales in SILS [11].

The Vinci robot system has been used with some success in single incision laproscopic surgery enabling three dimensional visualization thereby reducing the technical challenges posed by single site surgery [12].

Large series of SILS had been reported by Rewas et al. in 2009 comprising of hundred cases with conversion in $13 \%$ and no complication using SILS port [13]. White in 2009 published 6\% conversion and 4\% complications in his series of 100 cases [14]. Erbella in 2010 reported 100 cases with $2 \%$ conversion using similar technique [15]. Curcillo in 2010, had a conversion rate of $8.7 \%$ in 297 cases [16]. Antonio et al. reported a meta-analysis of 29 studies of 1166 patients undergoing SILS for cholecystectomy with conversion in $0.4 \%$ cases [17].

Only 3 SILS laproscopic colorectal surgeries have been reported. Leroy et al. reported SILS colorectal surgery with no conversions [18]. Larger series of SILS spleenectomy has been published by Targorona et al. In his series of 8 cases, conversion was required in 2 cases, the blood loss was $<100 \mathrm{ml}$ and the spleen weight $<500$ g. It offered better cosmesis, fewer complications, enhanced patient recovery but evidence was scarce [19].

Lee et al. described single port access laproscopic assisted vaginal hysterectomy in 4 cases and concluded that it was safe and effective [20]. Langebrekke and Ovistad described total laproscopic hysterectomy through single port as a better cosmetic alternative to conventional laproscopic hysterectomy [21].

\section{Conclusion}

Single port surgery has left its mark in Minimal Access Surgery. All initial studies showed it to be feasible, reasonably safe and cosmetically better than standard laproscopy. Experienced laproscopic skills are needed to accomplish safe single port surgery. The cost factor of the access devices and instrumentation is significantly more. Even with the best SILS instrumentation currently available the SILS approach imposes restriction on instrument manipulation, retraction and limits triangulation. It requires training and should be practiced in centers performing advanced laproscopic surgery. The advantages of single access surgery are better cosmesis, less bleeding, reduced infection and herniations. The existing evidence suggests that SILS is similar to standard laparoscopic surgery in terms of complication rates, completion rates and post-operative pain scores. Sils procedure has better cosmesis and decreased pain but cost is a limiting factor. Sils procedure should be practiced at advanced laparoscopic and minimal access centres and requires training for surgeon and proper instrumentation.

\section{REFERENCES}

[1] A. N. Kalloo, V. K. Singh, S. B. Jagannath, H. Niiyama, S. L. Hill, C. A. Vaughn, et al., "Flexible Transgastric Peritoneoscopy: A Novel Approach to Diagnostic and Therapeutic Interventions in the Peritoneal Cavity," Gastrointestinal Endoscopy, Vol. 60, No. 1, 2004, pp. 114117. doi:10.1016/S0016-5107(04)01309-4

[2] M. T. Gettman, Y. Lotan, C. A. Napper and J. A. Cadeddu, “Tansvaginal Laparoscopic Nephrectomy: Development and Feasibility in the Porcine Model,” Urology, Vol. 59, No. 3, 2002, pp. 446-450. doi:10.1016/S0090-4295(01)01568-0

[3] G. V. Rao, D. N. Reddy and R. Banerjee, "Notes: Human Experience,” Gastrointestinal Endoscopy Clinics of North 
America, Vol. 18, No. 2, 2008, pp. 361-370. doi:10.1016/j.giec.2008.01.007

[4] D. Rattner and A. Kalloo, “ASGE/SAGES Working Group on Natural Orifice Transluminal Endoscopic Surgery,” Surgical Endoscopy, Vol. 22, 2008, pp. 2279-2280.

[5] G. R. Limke, I. Tarantino, R. Hoetzel, R. Narschkow, J. Lange, R. Lachat, et al., "Tranvaginal Rigid-Hybrid NOTES Cholecystectomy: Evaluation in Routine Clinical Practice,” Endoscopy, Vol. 42, No. 7, 2010, pp. 571-575. doi:10.1055/s-0029-1244159

[6] G. P. Haber, S. Crowzet, K. Kamoi, A. Berger, M. Aron, R. Goel, et al. "Robotic NOTES (Natural Orifice Translumenal Endoscopic Surgery) in Reconstructive Urology: Initial Lab Experience,” Urology, Vol. 71, No. 6, 2008, pp. 996-1000. doi:10.1016/j.urology.2008.03.023

[7] K. Sumiyama, C. J. Gostout and M. T. Getlman, "Status of Access and Closure Techniques for NOTES,” Journal of Endourology, Vol. 23, No. 5, 2009, pp. 765-771. doi:10.1089/end.2008.0159

[8] G. Navarra, E. Pozza, S. Occhionorelli, P. Carcoforo and I. Donini, "One-Wound Laparoscopic Cholecystectomy," British Journal of Surgery, Vol. 84, No. 5, 1997, p. 695. doi:10.1046/j.1365-2168.1997.02586.X

[9] A. Rane, P. Rao and P. Rao, "Single Port Access Nephrectomy and Other Laparoscopic Urologic Procedures Using a Novel Laparoscopic Port (R-Port),” Urology, Vol. 72, No. 2, 2008, pp. 260-263. doi:10.1016/j.urology.2008.01.078

[10] I. S. Gill, A. P. Advincula, M. Aron, J. Caddedu, D. Canes, P. G. Curcillo, et al., "Consensus Statement of the Consortium for Laparoendoscopic Single-Site Surgery," Surgical Endoscopy, Vol. 24, No. 4, 2010, pp. 762-768. doi:10.1007/s00464-009-0688-8

[11] F. Bresadola, A. Pasqualucci, A. Donini, P. Chiarandini, G. Anania, G. Terrosu, et al., "Elective Transumblical Compared with Standard Laparoscopic Cholecystectomy,” European Journal of Surgery, Vol. 165, No. 1, 1999, pp. 29-34. doi:10.1080/110241599750007478

[12] M. A. White, G.-P. Haber and J. H. Kaouk, "Robotic Single-Site Surgery," Current Opinion in Urology, Vol. 20, No. 1, 2010, pp. 86-91. doi:10.1097/MOU.0b013e3283337a10
[13] H. Rivas, E. Varela and D. Scott, "Single-Incision Laparoscopic Cholecystectomy: Initial Evaluation of a Large Series of Patients," Surgical Endoscopy, Vol. 24, No. 6, 2010, pp. 1403-1412. doi:10.1007/s00464-009-0786-7

[14] W. M. White, G.-P. Haber, R. K. Goel, S. Crouzet, R. J. Stein and J. H. Kaouk, "Single-Port Urological Surgery: Single-Center Experience with the First 100 Cases," Urology, Vol. 74, No. 4, 2009, pp. 801-804. doi:10.1016/j.urology.2009.04.030

[15] J. Erbella and G. M. Bunch, "Single-Incision Laparoscopic Cholecystectomy: The First 100 Outpatients," Surgical Endoscopy, Vol. 24, No. 8, 2010, pp. 1958-1961. doi:10.1007/s00464-010-0886-4

[16] P. G. Curcillo, A. S. Wu, E. R. Padolsky, C. Graybeal, N. Katkhouda, A. Saenz, et al., "Single-Port-Access (SPA ${ }^{\mathrm{TM}}$ ) Cholecystectomy: A Multi-Institutional Report of First 297 Cases,” Surgical Endoscopy, Vol. 24, No. 8, 2010, pp. 1854-1860. doi:10.1007/s00464-009-0856-X

[17] S. A. Antoniou, R. Pointner and F. A. Granderath, "Single Incision Laparoscopic Cholecystectomy: A Systematic Review,” Surgical Endoscopy, Vol. 25, No. 2, 2011, pp. 367-377.

[18] J. Leroy, R. A. Cahill, M. Asakuma, B. Dallemagne and J. Marescaux, "Single-Access Laparoscopic Sigmoidectomy as Definitive Surgical Management of Prior Diverticulitis in a Human Patient," Archives of Surgery, Vol. 144, No. 2, 2009, pp. 173-179. doi:10.1001/archsurg.2008.562

[19] E. M. Targorona, C. Balague, C. Martinez, L. Pallares, L. Estalella and M. Trias, "Single-Port Access: A Feasible Alternative to Conventional Laparoscopic Splenectomy,” Surgical Innovation, Vol. 16, No. 4, 2009, pp. 348-352.

[20] Y.-M. Lee, T.-J. Kim, C. J. Kim, H. Kang, C. H. Choi, J.W. Lee, et al., "Single-Port Access Laparoscopic Assisted Vaginal Hysterectomy: A Novel Method with a Wound Retractor and Glove,” The Journal of Minimally Invasive Gynecology, Vol. 16, No. 4, 2009, pp. 450-453. doi:10.1016/j.jmig.2009.03.022

[21] A. Langebrekke and E. Quigstad “Total Laparoscopic Hysterectomy with Single-Port Access without Vaginal Surgery," The Journal of Minimally Invasive Gynecology, Vol. 16, No. 5, 2009, pp. 609-611. doi:10.1016/j.jmig.2009.06.003 